\title{
sciendo
}

\section{Final Consumption and Foreign Trade for Romania and European Union - A Granger causality-based analysis}

\author{
Mihai PĂUNIC̆ \\ Bucharest University of Economic Studies, Bucharest, Romania \\ mihai.paunica@cig.ase.ro \\ Alexandru MANOLE \\ “ARTIFEX” University of Bucharest, Bucharest, Romania \\ amanole@artifex.org.ro \\ Cătălina MOTOFEI \\ Bucharest University of Economic Studies, Bucharest, Romania \\ catalina.motofei@cig.ase.ro \\ Gabriela-Lidia TĂNASE \\ Bucharest University of Economic Studies, Bucharest, Romania \\ gabriela.tanase@cig.ase.ro
}

\begin{abstract}
In this paper, the authors seek to analyze if the relationship between final consumption and foreign trade indicators, at a macroeconomic level, manifests as a Granger causality. The graphical representation of the datasets reveals that the evolutions follow a similar pattern (with the exception of the net export). The indicators on both sides of the causality have been widely approached by researchers, as they contribute to the formation of the Gross Domestic Product. The research methodology follows the Toda-Yamamoto procedure for measurement of Granger causality, as the variables were expected to be (and were found to be in the initial step of the data analysis) non-stationary, and the results on the processing in levels can provide more accurate information. The research hypotheses were designed in order to detail the main topic of the paper on foreign trade indicators. None of the hypotheses has been validated, and the authors consider, in the future, the application of other methods to assess the quantitative side of the links between foreign trade and final consumption. The authors consider that a significant contribution brought by this study is the type of data analysis method applied and the approach towards the two macroeconomic components of the economy, for the cases of Romania and the entire European Union, of which Romania is a member.
\end{abstract}

Keywords: Granger causality, final consumption, foreign trade, Toda-Yamamoto procedure, data, analysis.

\section{Introduction}

Consumption and trade (import and export) have both been extensively studied in the literature, as two of the main elements that have a connection with a country's development. The connections between consumption and economic development and between trade and the gross domestic product are generally known and accepted. Bidirectional causality links can be found between output and trade (measured through imports and exports) in short and long run situations in 11 African countries, thus supporting the idea that exterior commerce will have an impact on economic growth, in the same way, that the renewable energy consumption will positively influence the GDP (Aïssa et all., 2014). Economic growth is also influenced by natural gas consumption and real trade in the particular case of Tunisia (Farhani et al., 2014). 
However, in light of this, we can't stop wondering if a connection can be made between consumption and trade. Does trade, namely imports and exports, exert an influence on consumption? And if that is the case, will an increase in trade reduce the final consumption, or is it the other way around? Such a connection has been less approached in the international literature, but nevertheless is of great importance for the economic development of a country. By understanding the way that international trade influences the final consumption, a country can implement import and export policies that will improve consumption and, in the end, the gross domestic product. At the same time, consumers can influence the trade policy, which will impact economic growth.

So, by taking into account these questions and the importance of trade and consumption for economic development, the main objective of this paper is to analyze the Granger causality connection between Final Consumption and Foreign Trade for Romania and the European Union.

The authors considered in the present paper the relationship between final consumption and foreign trade indicators: total imports and exports, net export, imports and exports of goods, and the net export of goods. In accordance with our hypothesis, the export is expected to increase when internal demand, of which final consumption can be considered an indicator, decreases. Also, the increase of final consumption, and therefore demand, is expected to lead to a growth of imports, when the internal market cannot offer enough to cope with the demand. The dataset is built by considering the values in the same year for all the indicators, taking into account the necessity of the supplier to adapt relatively quickly to the evolution of the demand.

Given the conclusions drawn from the literature review section, the following research hypotheses have been defined:

H1. There is Granger causality between final consumption and export of goods and services, both in terms of actual values and elasticities, for Romania and the European Union.

H2. There is Granger causality between final consumption and import of goods and services, both in terms of actual values and elasticities, for Romania and the European Union.

H3. There is Granger causality between final consumption and net export of goods and services, both in terms of actual values and elasticities, for Romania and the European Union.

H4. There is Granger causality between final consumption and export of goods, both in terms of actual values and elasticities, for Romania and the European Union.

H5. There is Granger causality between final consumption and import of goods, both in terms of actual values and elasticities, for Romania and the European Union.

H6. There is Granger causality between final consumption and net export of goods, both in terms of actual values and elasticities, for Romania and the European Union.

The authors consider that the six hypotheses allow an analytical approach towards the assessment of the more generalized Granger causality between foreign trade and final consumption.

We believe that our study will offer new theoretical insight in respect to the way trade can influence consumption overall, a field that is not thoroughly approached in the literature. Moreover, our findings may have importance also for policymakers. By better understanding the connection between consumption and trade (both imports and export), countries can adopt solutions and actions that can lead to an improvement of economic growth.

We focused our attention on European Union due to the economic similarities between the economies of the countries, and also on Romania due to our professional and personal interest (as citizens of this country) regarding the economy of this country.

The remainder of the paper is structured as follows: literature review, methodology, results and discussions, and conclusions. 


\section{Literature review}

Although our main objective is to analyze the connection between consumption and trade, if we take a look at the literature review available to us, we can see that most of the previous studies related to the influence of trade on energy consumption, as part of the final consumption, and the importance of renewable energy.

From our knowledge, the studies that approach the link between consumption and imports, respectively exports are scarce. This is one of the reasons we do the present study, to address the gap in the literature. But we start from what we know: that the international literature acknowledges and intensively studies the connection between energy consumption and trade. And if consumption is influenced by trade in the particular case of energy, we want to see if consumption overall can also be affected by imports and exports.

In regards to energy consumption and trade, a bidirectional connection can be seen between natural gas consumption and trade in the particular case of Tunisia (Farhani et al., 2014). In 15 Asian countries, a bidirectional causality connection can be found between trade openness and energy consumption (Nasreen \& Anwar, 2014). The same bidirectional connection can be found in the particular case of Belgium, both in the long and short-run, energy consumption and trade negatively affecting each other (Dogan, 2016). In the case of Egypt, an increase or a decrease in trade openness will generate a positive influence on the long and short run on energy consumption (Alkhateeb \& Mahmood, 2019). In other words, in general, if the trade increases, the energy demands will be affected due to the significant statistical connection between energy consumption and trade (Najarzadeh et al., 2015), although the existence of a positive or negative effect cannot be generalized.

However, it may all depend on the type of trade (import or export) and the type of energy consumption (renewable or non-renewable energy). Thus, a rise in export can generate an increase in energy consumption, will a rise in imports may result in a decrease (Najarzadeh et al., 2015).

Regarding the type of energy used, a study performed on 25 OECD countries reveals that in the short run, bidirectional causality links can be found between renewable energy consumption and imports, and between non-renewable energy consumption and both imports and exports, while a unidirectional connection from exports to renewable energy consumption can also be found (Jebli et al, 2016). Contrary to this, a study regarding 24 Sub-Saharan African countries supports the idea of a unidirectional short-term causality link from trade (both imports and exports) to renewable energy consumption (Jebli et al., 2015), while a study regarding the case of Tunisia reports a bidirectional connection between renewable energy consumption and international trade, also in short-run (Brini et al., 2017). Other authors (Jebli \& Youssef, 2015) confirm the existence, in the short run, of a bidirectional causality link between non-renewable energy and trade and a unidirectional connection from renewable energy to trade, while, in the long run, renewable energy and import have a bidirectional causality link, unlike the unidirectional connection that goes from renewable energy to export.

One reason for the mixed results that can be found in the literature, may be one important variable: energy price. Trade openness increases energy consumption in the long run, which in turn will increase the energy price, which may have a negative impact on energy consumption (Arif et al., 2017).

Other studies consider that trade has no direct effect on renewable energy consumption, but an indirect connection can be made through the transfer of technology (Aïssa et al., 2014). Exterior, international trade will facilitate the transfer of technology (Aïssa et al., 2014; Jebli et al, 2015; Brini et al., 2017; Jebli \& Youssef, 2015; Arif et al., 2017; Nasreen \& Anwar, 2014) between 
countries and will improve renewable energy capabilities and consumption. In turn, the renewable energy will contribute to the decrease of $\mathrm{CO} 2$ emissions and will reduce the energy dependency of a country (Jebli et al., 2013).

Or, the connection between trade and energy consumption can be influenced by the level of economic development of a country. A study made on 91 countries reveals that in high-income countries the link between trade and energy consumption has the shape of an inverted U, as opposed to the one in low- and middle-income countries, where the connection has the shape of a normal U, although the two variables have a bidirectional causality link (Shahbaz et al., 2014). Păunică et.al. (2019) have analyzed the Granger causality between remittances and household consumption.

There are also studies that debate the relationship between production, consumption, and trade of a variety of crops. The general idea is that if the consumption increases, in order to meet the demand of a country, the imports of crops should also increase, or else, if the supply is short, the consumption will decline (Reddy, 2004). An increase in imports is costly and will determine an increase in crops prices (Reddy, 2004), which in turn will impact the economy. So, broadly speaking, consumption can impact imports and also exports (if internal consumption need is high, in theory, the level of exports will be lower).

So, if trade, namely imports and exports influences energy consumption and crop consumption, will it also have an impact on the final consumption of a country? The main objective of our paper is to answer this question and to analyze, using the Toda-Yamamoto approach of the Granger causality connection, the link between final consumption and trade.

\section{Methodology}

Data that define the variables included in each research hypothesis have been collected from the EUROSTAT database, on February $5^{\text {th }}, 2021$. The data source is the table "GDP and main components (output, expenditure, and income) [NAMA_10_GDP_custom_539279]", its metadata indicate that the last update and last change of data structure occurred on February $2^{\text {nd }}, 2021$. All indicators are measured in "Current prices, million purchasing power standards [CP_MPPS]", and frequency is annual. The indicators selected according to the research hypotheses are the following:

a. "Final consumption expenditure [P3]", coded $F C$ in this article;

b. "Exports of goods and services [P6]" (code EX);

c. "Exports of goods [P61]" (code EG);

d. "Imports of goods and services [P7]" - code IM;

e. "Imports of goods [P71]" - code $I G$.

f. Net export, code $N E$.

All indicator codes carry the prefix $R$ for Romania and $E$ for the European Union: "European Union - 28 countries (2013-2020)". The elasticities carry $L$ as their first letter.

The research methodology on which the authors have aimed to validate the research hypotheses is the Toda-Yamamoto procedure, implemented in EViews ${ }^{\circledR}$, by adapting the guidelines of Giles (2011) to the number of observations:

a. Measurement of the maximum degree of integration for the pair of variables used to describe the research hypothesis. The variables have been checked for stationarity/unit root by using the following tests:

- Augmented Dickey-Fuller, for a maximum of five lags, automatic lag selection based on the Schwarz Info Criterion, the option ,trend and intercept”;

- Philips-Perron, with the default settings, presented in figure 1. 


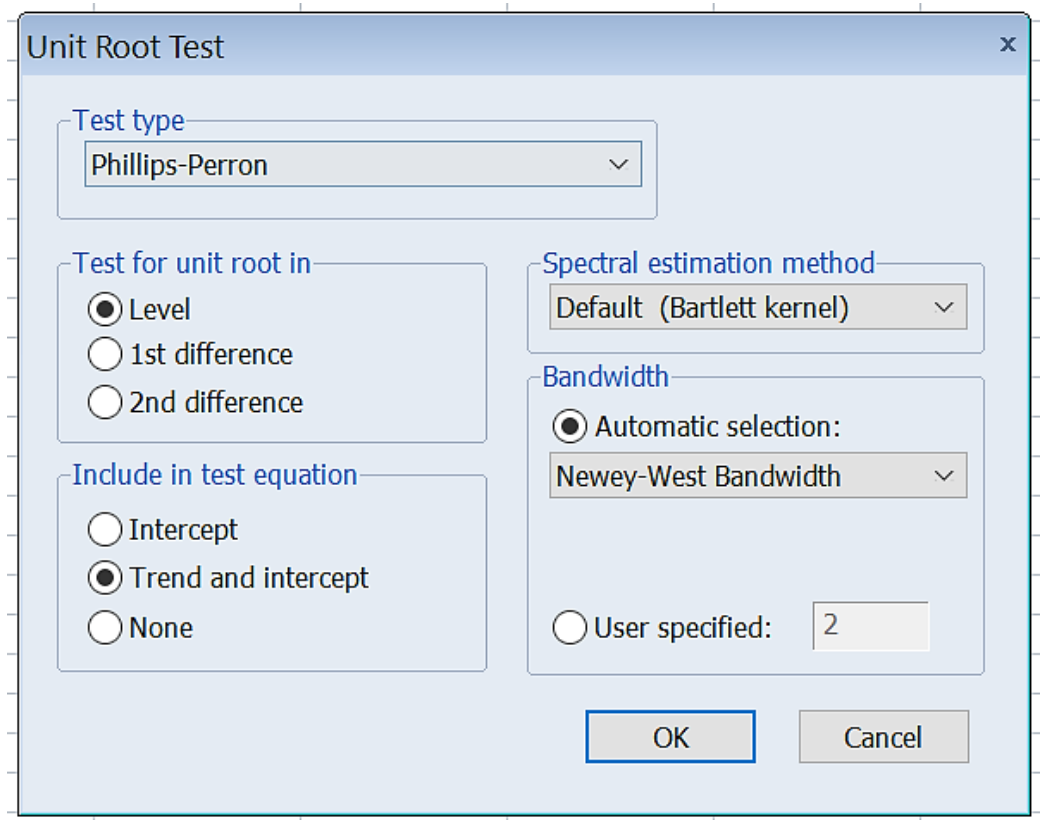

Figure 1. Configuration for the Phillips-Perron unit root test

Source: authors' capture from EViews ${ }^{\circledR}$.

b. Definition of a VAR model between the two variables, initially using the default lag length set by the software, that is 2 .

c. Re-configuration of the $\operatorname{VAR}(2)$ model to the optimum lag length (by using EViews standard tests, as there are five tests and conflicting results can occur, the preferred value was the one associated with the SC instrument).

d. Test of the re-configured VAR model against the four specification tests:

- AR Roots test for stability;

- Autocorrelation LM test. For this instrument, all models have been tested against 12 lags;

- Normality (the first option of the software interface has been used, that is the "Cholesky of covariance (Lutkepohl) orthogonalization method";

- Heteroskedasticity (as in the case of normality, the default option has been kept "White Heteroskedasticity (No Cross Terms)".

According to the test results, the decision to pass to the next step followed two rules:

- In case of unsatisfactory results returned by AR or Autocorrelation, the lag length was gradually increased by unit (see Giles, 2011);

- If either normality or heteroskedasticity test failed, the model is deemed unsuitable for further analysis, as results can be biased (see Hacker \& Hatemi-J, 2003);

e. The results are cross-checked with the Johansen cointegration test, the option "Trend assumption: Linear deterministic trend (restricted)", according to the rules specified in Giles (2011) if the variables have the same order of integration.

f. The model that passed the tests is re-configured by inserting the lagged variables up to the maximum order of integration, as exogenous variables (see Giles, 2011);

g. The updated model is tested for Granger causality. 


\section{Results and discussions}

The values of the indicators that characterize the Romanian economy, in nominal values, are described in figure 2 .
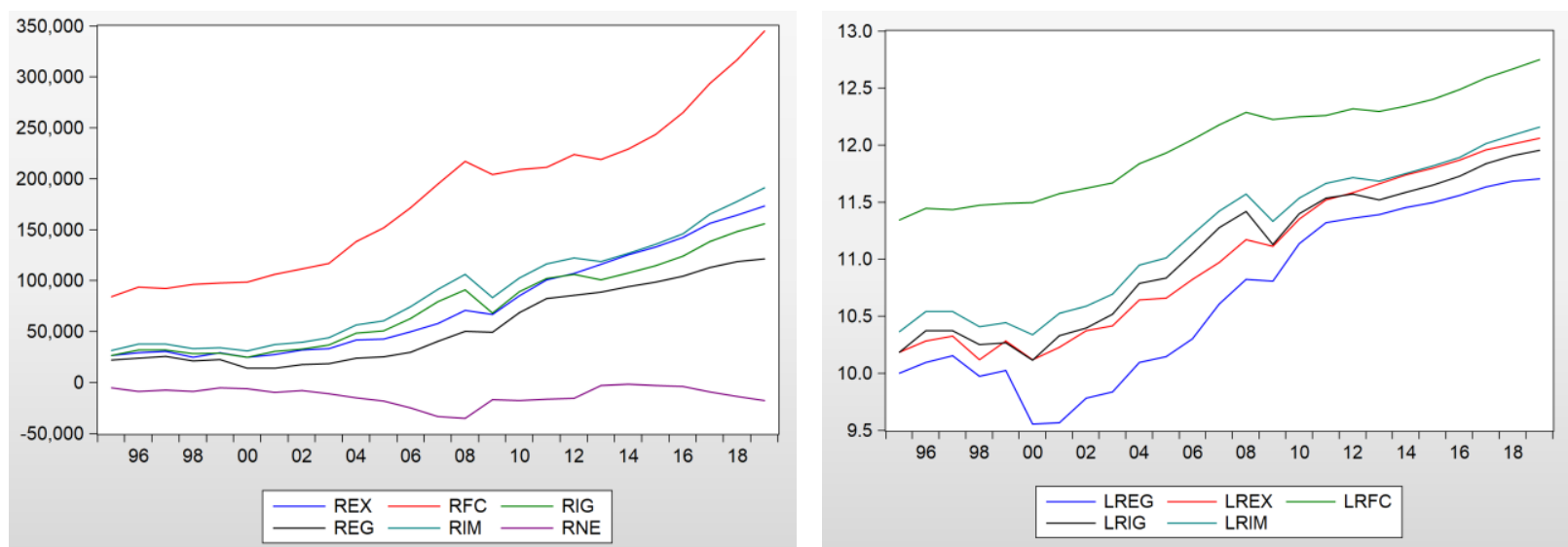

PICBE |

843

Figure 2. Nominal values and elasticities of the indicators, for Romania

Source: authors' representations in EViews ${ }^{\circledR}$.

It can be observed that the foreign trade indicators, with the exception of the net export, follow a similar pattern of evolution as the final consumption, which allows the conclusion that there must be some type of connection between the indicators (the authors pursue, in this paper, the estimation of Granger causality, crosschecked with cointegration). The same observation applies to the elasticities, which is normal. However, there is no elasticity for the Romanian net export, as all values of the indicator are negative. Therefore, the final hypothesis can be tested only for the European indicators, whose evolution is graphically represented in figure 3.
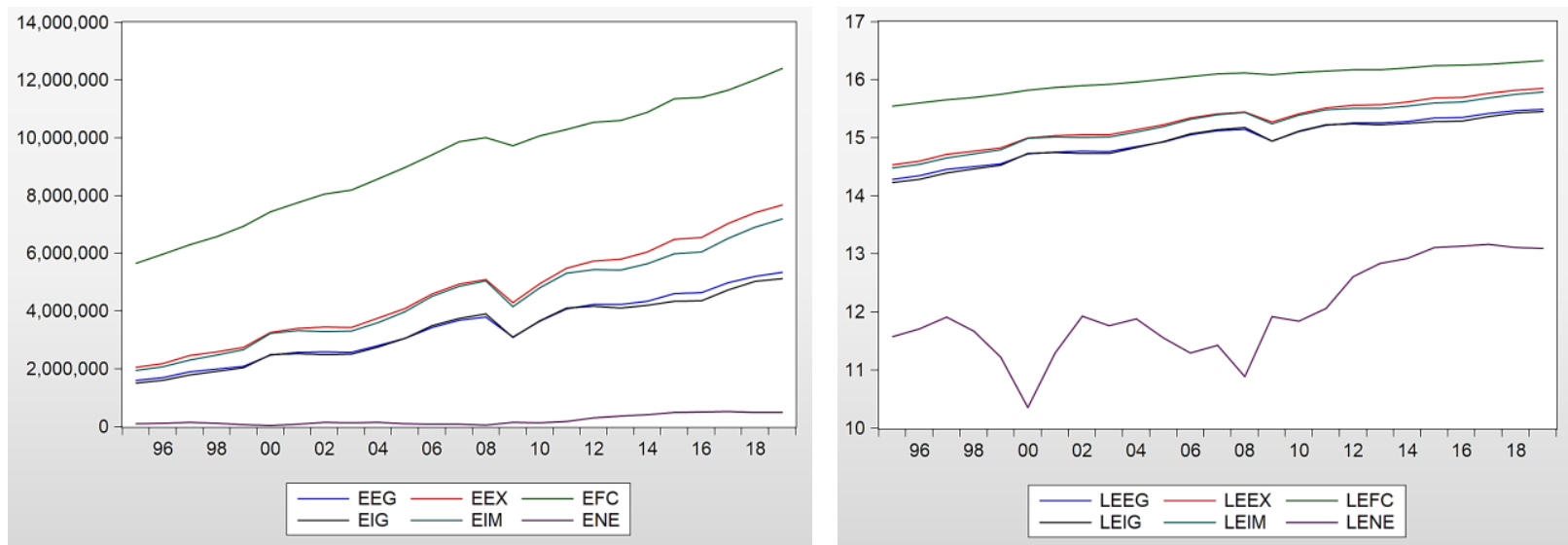

Figure 3. Nominal values and elasticities of the indicators, for European Union

Source: authors' representations in EViews ${ }^{\circledR}$.

The same observation made for the Romanian indicators is valid for the European Union case: there are similarities in the patterns displayed by the dependent variable and its factors of causality, in Granger sense.

As the graphical representations do not contradict the research hypothesis, they are going to be tested according to the proposed methodology. 


\section{Testing H1 - Romania (nominal values)}

The export is I(1), while the final consumption is I(2). Thus, the maximum order of integration is 2 , and the variables are not cointegrated, which prevents the use of the cross-check test.

After estimating a VAR model between the two variables, the optimum lag length is 3 . The VAR(3) is not stable, and remains in this state until the maximum acceptable lag length, as VAR(6). Even if the other tests are passed in VAR(3), the authors defer to Giles(2011) rules, therefore a stable model is preferred to an unstable one, and this model will not be used to test for Granger causality.

\section{Testing H1 - Romania (elasticities)}

The unit root tests for the final consumption are contradictory, while ADF indicates I(2), PP testifies for I(1). The authors will consider the maximum value, as the finality of this step is the maximum order of integration. For the elasticity of export, both tests demonstrate a degree of integration of 1 , the variables cannot be tested for cointegration.

The optimum (SC) lag length remains 2 but is not stable. The VAR(3) is stable but encounters autocorrelation in the residuals. VAR(4) satisfies all specification tests and is augmented with the additional exogenous variables reflecting the maximum order of integration. The "VAR Granger Causality/Block Exogeneity Wald Tests" does not indicate the presence of any Granger causality between the two variables.

\section{Testing H1 - European Union (nominal values)}

The final consumption is I(1), according to both tests applied, and the same order of integration is found for exports. Schwarz Criterion indicates a VAR(1) as the optimum lag configuration between $E E X$ and $E F C$. The model is affected by non-normal residuals, making it unsuitable for further analysis.

When cross-checked by the cointegration test, one of the results is "Max-eigenvalue test indicates 1 cointegrating eqn(s) at the 0.05 level". According to Giles (2011), the presence of cointegration indicates that at least one Granger causality must exist. Even if the failure to comply with normality assumption is not considered, the updated VAR model demonstrates the absence of Granger causality. An explanation for such contradictory results is the small size of the sample, as indicated by Giles(2011).

\section{Testing H1 - European Union (elasticities)}

Both variables are I(1). The optimum configuration for the core instrument of the procedure is VAR(1). There is autocorrelation in the residuals up until the model becomes VAR(6).

None of the tests related to the first research hypothesis testified for the presence of causality. The first explanation, in the opinion of the authors, is the behavior caused by the datasets. The only model suitable for testing includes the Romanian elasticities, but no Granger causalities occurred. For the EU models, the behavior of both models is not according to the results of the Johansen cointegration test (even if the absence of Granger causality indicated by VARs with normality issues is not necessarily a trustworthy result).

The H1 hypothesis cannot be validated. 


\section{Testing H2 - Romania (nominal values)}

The import is I(1), therefore the maximum order of integration is 2 . No stable model can be estimated for the two variables; therefore, the procedure cannot be further pursued. As the orders of integration are not identical, no cross-checking can be made (Giles, 2011).

\section{Testing H2 - Romania (elasticities)}

The maximum order of integration is 2 . The $\operatorname{VAR}(2)$, optimum configuration, is not stable, so is updated to VAR(3). Even if stable and with no serial correlation in the residuals, the results are not multivariate normal. The model cannot be used further, and there is no possibility to test for cointegration.

\section{Testing H2 - European Union (nominal values)}

The maximum order of integration, for the imported variable, is not the same, according to the tests ( 0 in the case of ADF, 1 reported by PP). The value does not influence the maximum order of integration, as $E F C$ is I(1). SC reports that the optimum lag length is 1 . The model is stable, free from autocorrelation, but there are normality issues. Having no cointegration at the chosen level of significance, the results are not contradictory within the test procedure.

\section{Testing H2 - European Union (elasticities)}

Following the application of the unit root tests, the same orders of integration as in the case of nominal values are found. For the best VAR(1) model, the autocorrelation LM test leads to the rejection of the null hypothesis at lag 7 . VAR(2) has no issue of stability or autocorrelation, but the normality of residuals is not validated. There is no cointegration and Granger causality cannot be tested according to the rules for model specification.

The H2 hypothesis cannot be verified.

\section{Testing H3 - Romania (nominal values)}

Unsurprisingly, as it is calculated on the basis of the causal variables, the net export is I(1), giving a maximum order of integration of 2 . Starting as the lag length of 3, the model cannot be declared to be stable, even if as VAR(6).

\section{Testing H3 - European Union (nominal values)}

The maximum order of integration is 1 , as is the optimum lag length. Up until lag length becomes $1 . .4$, the model is unstable, while VAR(4) displays serial correlation in residuals at lag 7. Increasing further the lag length leads to loss of model stability. There is no cointegration, so, as far as the methodology allows, the results are not satisfactory, but there is no contradiction either.

\section{Testing H3 - European Union (elasticities)}

After estimating the VAR(1) as optimum lag length, all specification tests are complying with the statistical assumptions, and no cointegration is found. By adding the variables corresponding to the lags for the maximum order of integration, the model can be tested for Granger causality, but the test coefficients indicate that no such causality exists, either one-way or bi-directional.

As none of the tests indicated Granger causality, the H3 hypothesis is not validated. 


\section{Testing H4 - Romania (nominal values)}

The initial parameters are the lag length of $1 \ldots 3$ and the maximum order of integration (2). The VAR established between the two variables is not stable, even if lag length reaches 1...6.

\section{Testing H4 - Romania (elasticities)}

SC indicates that the optimum test model must be specified as VAR(3). The model is stable but needs adjustment because of autocorrelation. Models with more extended lag lengths are not stable, and therefore not usable, from the viewpoint of proper specification.

\section{Testing H4 - European Union (nominal values)}

The export of goods is found to be stationary, given the maximum order of integration to be 1 . The test model starts from a single lag (1), is stable, and has no autocorrelation issues. However, the normality of the residuals prevents the further application of our methodology, and there is no possibility to check for cointegration.

\section{Testing H4 - European Union (elasticities)}

The variables have the same order of integration, 1. The optimum test model is VAR(1). The specification tests display autocorrelation in residuals - lag 12. After being adjusted to lag length $1 . .2$, the model is stable, free from autocorrelation, but fails the normality test. The fact that the cointegration test indicates cointegrating equations by both Trace and Max-eigenvalue, means that the dataset "hides" at least one Granger causality. Applying the procedure without regard towards the normality issue indicates no Granger causality but, again, this result is not to be fully trusted.

The results of the analysis do not allow the validation of the $\mathrm{H} 4$ hypothesis.

\section{Testing H5 - Romania (nominal values)}

The optimum lag length for the test VAR is $1 \ldots 4$, for a maximum order of integration 2 . However, no stable model can be estimated between the variables.

\section{Testing H5 - Romania (elasticities)}

Starting with a VAR(3) model, the failure of the autocorrelation LM test induces an increase of the maximum lag length. Component 1 of the normality test displays improper values, rending the model unsuitable for further testing.

\section{Testing H5 - European union (nominal values)}

As the unit root tests do not return the same value, the maximum of these is considered, and the import of goods is valuated as I(1). This choice has no effect on the methodology, as the dependent variable is $\mathrm{I}(1)$. More than one lag of the VAR(1) model is affected by serial correlation in residuals, while no such issue occurs for $\operatorname{VAR}(2)$. There is no cointegration between the variables, but the model fails the normality test.

\section{Testing H5 - European union (elasticities)}

The initial steps of the methodology reveal the same order of integration (1) and the VAR(1) as the optimum (according to SC) model. The autocorrelation tests involve the rejection of the null hypothesis at lags 6 and 7, forcing an update to $\operatorname{VAR}(2)$, which passes both stability and autocorrelation tests, but not the normality one. As the two Johansen tests indicate the presence of cointegration, there is a contradiction between the results. Even if (on the basis of the Doornik- 
Hansen "square root of correlation" normality test and the fact that the heteroskedasticity test is passed) the model is configured for Granger causality testing, the null hypothesis of no causality cannot be rejected.

H5 cannot be validated.

\section{Testing H6 - Romania (nominal values)}

Even if the model is best estimated (Schwarz criterion) as VAR(1), no stability can be demonstrated up until VAR(6).

\section{Testing H6 - European Union (nominal values)}

Schwarz criterion indicates VAR(1) as the optimally estimated model. However, this model presents serial correlation in residuals, and the corrections applied to lead to a VAR(4) that is stable and without any serial correlation. The other two tests are passed as well, and the model is re-configured for Granger causality (by adding the fifth lags of the two variables, as exogenous parameters). No causality or cointegration is revealed by the tests.

The elasticity cannot be computed because of the negative values in the nominal datasets. Thus, the H6 research hypothesis cannot be validated.

\section{Conclusion}

As the hypotheses have been designed, and the research methodology was applied accordingly, no Granger causality was emphasized, for any of the cases tested. The fact that both nominal values and elasticities presented the same behavior during the test procedure substantiates, in the opinion of the authors, that data might be too few in order to fully benefit from the tests. Not all the models were well-specified and usable for the final phases of the assessment. Clearly, the number of observations available limits allows for more flexibility in adapting the core of the procedure - the VAR model to the tests (i.e., the initiative to add more lags in the situation described by the methodology). Overall, the conflicting results that we found by testing our hypotheses are similar to the mixt results that the literature review provides in regard to the connection between energy consumption and trade, leading us to believe that other variables may be of interest, such as prices, type of consumption, level of economic growth, transfer of technology, capital per labor, etc., as some of the international study mention. The authors consider that the availability of more data in the future might produce better results. Also, additional analysis methods, applied to the datasets describing the same indicators, can be more useful in providing relevant conclusions.

\section{References}

Aïssa, M. S. B., Jebli, M. B., \& Youssef, S. B. (2014). Output, renewable energy consumption and trade in Africa, Energy Policy, 66, 11-18.

Alkhateeb, T. T. Y., \& Mahmood, H. (2019). Energy consumption and trade openness nexus in Egypt: Asymmetry analysis, Energies, 12(10), 2018.

Arif, I., Kazmi, S. W., \& Khan, L. (2017). Relationship between trade openness and energy consumption in oil importing Asian countries, Journal of Finance \& Economics Research, 2(1), 37-53.

Ben Jebli, M., Ben Youssef, S., \& Ozturk, I. (2013). The environmental Kuznets curve: the role of renewable and non-Renewable energy consumption and trade openness, Munich Personal RePEc Archive. 
Ben Jebli, M., Ben Youssef, S., \& Ozturk, I. (2015). The role of renewable energy consumption and trade: Environmental kuznets curve analysis for sub-saharan Africa countries, African Development Review, 27(3), 288-300.

Brini, R., Amara, M., \& Jemmali, H. (2017). Renewable energy consumption, International trade, oil price and economic growth inter-linkages: The case of Tunisia, Renewable and Sustainable Energy Reviews, 76, 620-627.

Dogan, E. (2016). The relationship between economic growth, energy consumption and trade, Bulletin of Energy Economics, 4(1), 70-80.

Farhani, S., Shahbaz, M., Arouri, M., \& Teulon, F. (2014). The role of natural gas consumption and trade in Tunisia's output, Energy Policy, 66, 677-684.

Giles, D. (2011). Testing for Granger Causality, Retrieved from https://davegiles. blogspot.com/2011/04/testing-for-granger-causality.html, accessed February $14^{\text {th }}, 2021$.

Hacker, R.S., \& Hatemi-J, A., 2003. Tests for Causality Between Integrated Variables Based on Asymptotic and Bootstrap Distributions, Working Paper [2003:02], Department of Statistics, Lund University.

Jebli, M. B., \& Youssef, S. B. (2015). Output, renewable and non-renewable energy consumption and international trade: Evidence from a panel of 69 countries, Renewable Energy, 83, 799-808.

Jebli, M. B., Youssef, S. B., \& Ozturk, I. (2016). Testing environmental Kuznets curve hypothesis: The role of renewable and non-renewable energy consumption and trade in OECD countries, Ecological Indicators, 60, 824-831.

Najarzadeh, R., Reed, M., Khoshkhoo, A., \& Gallavani, A. (2015). Trade and Energy Consumption in the OPEC countries, Journal of Economic Cooperation \& Development, 36(1), 89.

Nasreen, S., \& Anwar, S. (2014). Causal relationship between trade openness, economic growth and energy consumption: A panel data analysis of Asian countries, Energy Policy, 69, 82-91.

Păunică, M., Manole, A., Motofei, C., \& Tănase, G.L. (2019). The impact of remittances on GDP and household consumption. An European union countries analysis, Economic Computation and Economic Cybernetics Studies and Research, 53(4), 97-114.

Reddy, A. A. (2004). Consumption pattern, trade and production potential of pulses, Economic and political weekly, 4854-4860.

Shahbaz, M., Nasreen, S., Ling, C. H., \& Sbia, R. (2014). Causality between trade openness and energy consumption: What causes what in high, middle and low income countries, Energy Policy, 70, 126-143. 